\title{
In vitro antioxidant and antimicrobial potential of Sterculia urens Roxb. root extract and its bioactive phytoconstituents evaluation
}

\author{
Anjali Shukla, Krishna Desai and Nainesh Modi
}

\begin{abstract}
Background: The plant Sterculia urens Roxb. of Malvaceae family is comparatively understudied. Genus Sterculia is widely recognized by its phytomedicinal and ethnomedicinal attributes. The study is aimed to evaluate the qualitative analysis, Fourier transform infrared (FT-IR), thin layer chromatography (TLC), total phenolic content (TPC), antioxidant and antimicrobial activities of the crude hydro-methanolic extract of $\mathrm{S}$. urens root.

Results: The antioxidant activity, antimicrobial assay for clinical isolates, and TPC were measured by DPPH (2,2-diphenyl1-picrylhydrazyl) free radical scavenging activity, agar well diffusion method, and Folin-Ciocalteu assay respectively. Hydromethanolic extract confirmed the presence of alkaloids, flavonoids, tannins, phenols, saponins, steroids, and glycosides as primary and secondary metabolites, which was later confirmed by TLC. FT-IR spectroscopy revealed the presence of alkanes, alkenes, alkyl halides, halogen compounds, primary alcohol, tertiary alcohol, aldehyde, aromatic amine, secondary amines, amide group, and carboxylic acid. The crude extract was composed of a significant quantity of total phenolic content with $705 \pm 0.40 \mathrm{mg} \mathrm{GAE} / \mathrm{g}$. Synergistically, the $\mathrm{IC}_{50}$ value of the crude extract and ascorbic acid was found to be $27.055 \mu \mathrm{g} / \mathrm{ml}$ and $37.244 \mu \mathrm{g} / \mathrm{ml}$, respectively, which suggests that root extract possesses strong antioxidant properties. The majority of the microbial strains exhibited varying degrees of sensitivity to the root extract with a notable inhibitory effect against Escherichia coli, Klebsiella pneumoniae, and Penicillium glaucum.

Conclusion: The findings of this analysis suggest that the hydro-methanolic extract from S. urens root exhibit antioxidant activity quantified by its ability to scavenge DPPH; antimicrobial activity displayed appreciable microbial sensitivity. These properties are associated with the presence of high phenolic content, different secondary metabolites, and their functional groups. The results are suggestive that $S$. urens root is rich in bioactive compounds, which serve as a novel natural source for potential therapeutic applications.
\end{abstract}

Keywords: Antimicrobial, Antioxidant, Phytochemistry, Root extract, Sterculia urens

\section{Statement of novelty}

Sterculia urens Roxb. is highly exploited for karaya gum due to commercial demand but remained unexplored for its pharmacological values. This work shows various secondary metabolites, phenolic content, antioxidant,

\footnotetext{
*Correspondence: nrmodi@gujaratuniversity.ac.in

Department of Botany, Bioinformatics and Climate Change Impacts

Management, School of Science, Gujarat University, Ahmedabad, Gujarat 380009, India
}

and antimicrobial potential of $S$. urens root. This primary information introduces a new arena for the discovery of bioactive ingredients useful for the manufacturing of new drugs.

\section{Background}

Every medicinal plant's remedial effects are associated with their distinct chemical properties; hence, they are the 'chemical factory' which yields compounds like

\section{Springer Open}

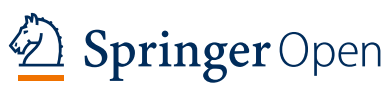

(c) The Author(s). 2020 Open Access This article is licensed under a Creative Commons Attribution 4.0 International License, which permits use, sharing, adaptation, distribution and reproduction in any medium or format, as long as you give appropriate credit to the original author(s) and the source, provide a link to the Creative Commons licence, and indicate if changes were made. The images or other third party material in this article are included in the article's Creative Commons licence, unless indicated otherwise in a credit line to the material. If material is not included in the article's Creative Commons licence and your intended use is not permitted by statutory regulation or exceeds the permitted use, you will need to obtain permission directly from the copyright holder. To view a copy of this licence, visit http://creativecommons.org/licenses/by/4.0/. 
saponins, terpenes, alkaloids, lactones, oleoresins, glycosides, resins, and essential or fixed oils [1]. For all living organisms, metabolism is necessary, and plants have two types called primary metabolites and secondary metabolites [2, 3]. Although secondary metabolites are reported lower than primary metabolites, they have considerable biological activities [4]. For that reason, the most promising source of novel biologically active substances that protect human from various diseases is medicinal plants [5].

Moreover, concerns about the adverse health effects are growing due to the industrial use of synthetic products. It has been shown that some synthetically manufactured antioxidants, including dibutylhydroxytoluene and butylated hydroxyanisol, promote carcinogenic activity $[6,7]$, while naturally obtained phenolic antioxidants are shown to manifest a variety of healthpromoting biological activities. Since the last few years, FT-IR has played a crucial role in scientific research; most recently, spectroscopy has made considerable advances in the area of clinical assessment and arose as one of the key tools for biomedical claims. Research on many different natural tissues utilizing spectroscopic techniques, such as FT-IR spectroscopy, has been adapted [8].

Natural products derived from plants such as terpenoids, alkaloids, and flavonoids have gained significant exposure for the past few years due to their various pharmacological properties, including antimicrobial, antioxidant, and anticancer activities [9]. Antioxidants are natural or artificial substances capable of preventing or limiting certain kinds of cell injuries. Antioxidants often are found in several plants produces, especially vegetables and fruits, and also readily available as food supplements [10]. Adequate intake of dietary antioxidants can boost defence against free radicals, as the plant-based natural antioxidants can scavenge nocuous free radicals generated in the human body. It is also suggested that the intake of antioxidant-rich foods plays a vital and beneficial role in preventing or postponing the onset of degenerative diseases [11]. Recently, high levels of bioactive compounds with good antioxidant potential have been found in the roots $[12,13]$.

The discovery of novel drugs from plants was encouraged by the resistance developed in pathogenic microbes against conventional antibiotics and oxidative stress produced by free radicals. A significant number of plants are recorded to possess antimicrobial and antioxidant properties [14]. Since ancient times, plants have been used to produce a range of chemical substances with medicinal value, including antidiabetic, anticancer, antimicrobial, antioxidant, and anti-inflammatory. The World Health Organization (WHO) also considers plants to be the ultimate source of numerous drugs and advocates the continued use of these herbal medicines to treat various microbial and non-microbial diseases [15].

Moreover, various plant genera are extensively explored for phytochemicals with regard to their ethnomedicinal properties. One of those genera includes Sterculia representing 200 species, predominantly distributed across tropical and subtropical regions. Plants which belong to this genus contain significant to the low amounts of flavonoids, terpenoids, phenolic acids, phenylpropanoids, alkaloids, and other metabolites, including carbohydrates, lipids, lignans, and lignin [16]. One such species of these genera is Sterculia urens Roxb. (Fig. 1) commonly known as 'gum karaya'; it is one of the critical commercial trees of India [17]. Earlier, it was kept under the family Sterculiaceae but currently belongs to the subfamily Sterculioideae and classified under family Malvaceae [16, 18]. In India, it is distributed across the sub-Himalayan range, Rajasthan, Madhya Pradesh, Andhra Pradesh, Maharashtra, Uttar Pradesh, Kerala, and Gujarat $[19,20]$. It offers numerous applications in food, dairy, beverages, cosmetic, textile, oil, and pharmaceutical sectors [18]. Therefore, this experiment is aimed to investigate the phytochemical profiles, including total phenolic content, thin-layer chromatography assay, and FTIR screening, along with antioxidant and antimicrobial activities of the $S$. urens root extract.

\section{Methods}

\section{Collection and authentication}

Sterculia urens Roxb. (gum karaya) was collected by the first author from Kansarvid, Banaskantha district, Gujarat, India, in August 2019 (latitude $24.26^{\circ} \mathrm{N}$ and longitude $72.51^{\circ} \mathrm{E}$ ); immediately, its identification and pre-treatment were carried out. The plant material was authenticated, and the herbarium specimen was deposited with reference ID (GUSU-01).

\section{Plant material}

The root samples appeared reddish within the cortex region (Fig. 2) and washed twice using deionized water (Milli-Q Millipore, $0.054 \mathrm{mS} / \mathrm{cm}$ ) to clean soil and dirt. The root sample was slightly scraped with a scalpel blade (No. 24), cut into pieces with $2.5 \mathrm{~cm}$ length each, sun-dried for 7 days, ground to a fine powder, and then stored for further analysis at $-20^{\circ} \mathrm{C}$.

\section{Preparation of plant extract}

The Soxhlet extraction method was used to prepare plant extract; $90 \%$ hydro-methanolic $(1: 9 \mathrm{v} / \mathrm{v})$ was used as an extracting solvent. This fresh solvent and solid residues (solid-to-solvent ratio, 1:10 g/ml) were placed in a $22 \mathrm{~mm} \times 80 \mathrm{~mm}$ extraction thimble [DWK Life Sciences (Wheaton), Mumbai, India] and extracted at $65^{\circ} \mathrm{C}$ with $90 \mathrm{ml}$ methanol and $10 \mathrm{ml}$ distilled water (D. W.) for 18 $\mathrm{h}$ with $4-5$ cycles/h. The collected extracts were filtered 


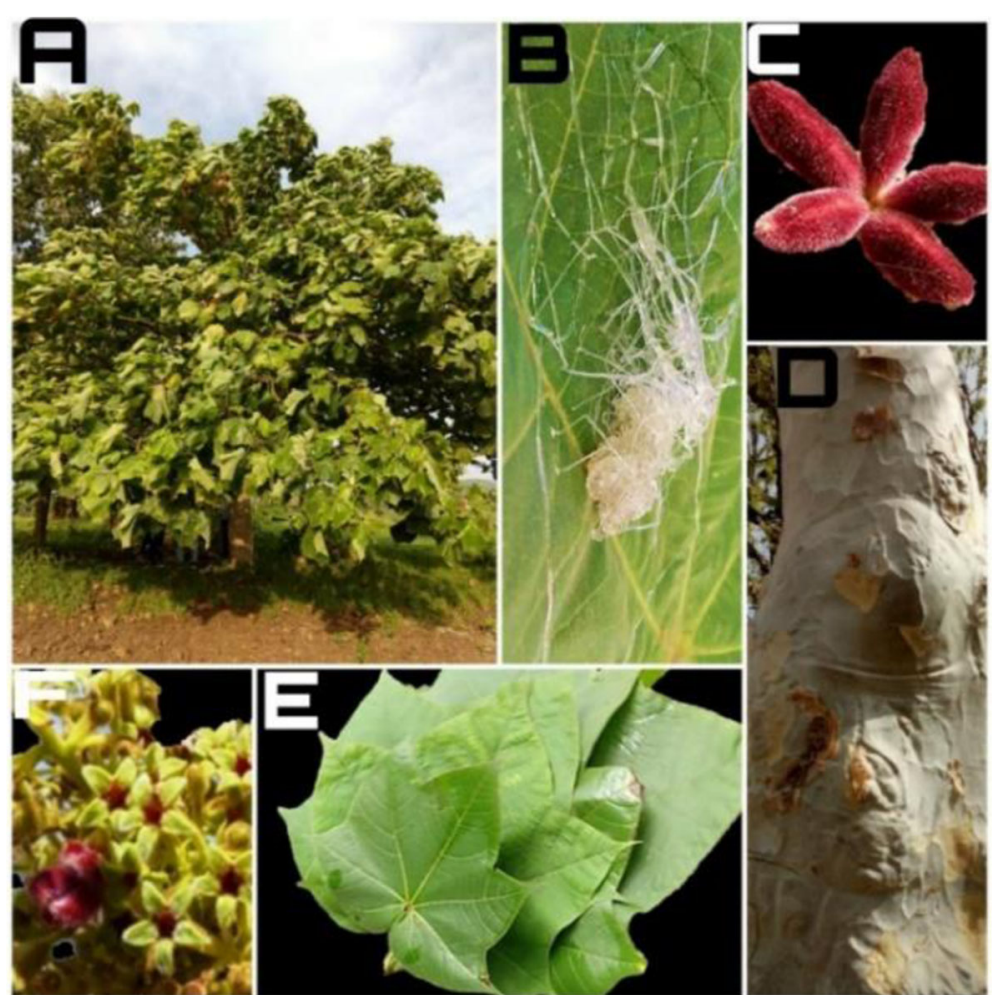

Fig. 1 Sterculia urens Roxb. a Tree. b Karaya gum. c Fruit. d Bark. e Leaf. f Flowers

with Whatman No. 1 filter paper, and the extra solvent was evaporated by rotary evaporator at reduced pressure for 30 min (IKA-RV10 Digital V, Karnataka, India) at a controlled temperature of $40^{\circ} \mathrm{C}$ and stored for further analyses at $4{ }^{\circ} \mathrm{C}$. Finally, the yield value of crude hydromethanolic extract was calculated by the given standard formula [21].

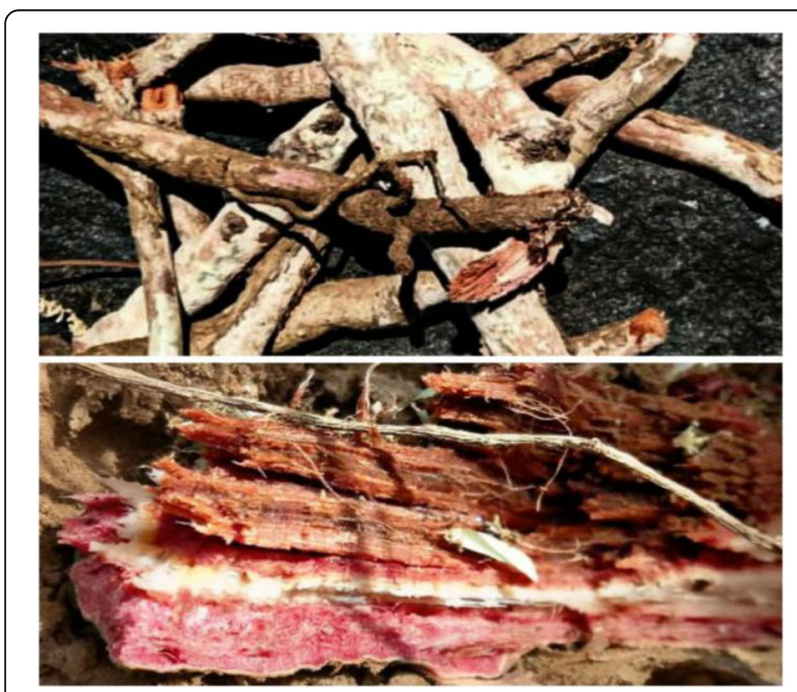

Fig. 2 Morphology of Sterculia urens Roxb. roots

$$
\text { Yield }(\%)=\frac{\text { Final weight of extract obtained }}{\text { Initial weight of extract }} \times 100
$$

\section{Reagents and chemicals}

The DPPH and the Folin-Ciocalteu phenol reagent were purchased from Sigma-Aldrich Co., Germany. Sodium carbonate $\left(\mathrm{Na}_{2} \mathrm{CO}_{3}\right)$ ethanol and gallic acid and were obtained from Himedia, India. The majority of the chemicals (AR: analytical grade) sourced in the present study were procured locally (India).

\section{Bioassays}

Preliminary phytochemical screening

Qualitative phytochemical analysis of crude extract determines the presence of compounds like sterols, glycosides, saponins, tannins, flavonoids, phenols, resins, and alkaloids using the standard protocol. The qualitative phytochemical screening of crude extracts was done using the methods described by the various workers $[22,23]$.

\section{Thin layer chromatography}

Dried root material was mixed with $\mathrm{MeOH}(100 \mathrm{mg} / \mathrm{ml})$, vortexed $(1.5 \mathrm{~min})$, and centrifuged $(10 \mathrm{~min}$ at $10,000 \mathrm{rpm})$. After removing the supernatant, the residues were reintroduced thrice to obtain a concentrated sample. Mobile phase for elution of phenolics (toluene to acetone; 9:1 v/v), 
alkaloids (toluene to diethylamine to methanol; 8:1:1 v/v), flavonoids (glacial acetic acid to ethyl acetate to formic acid to water; 0.5:10:0.5: $1.3 \mathrm{v} / \mathrm{v}$ ), steroids (butanol to methanol to water; 16:4:0.2 v/v), and Tannins (methanol to chloroform to water; 35:65:10 v/v) were considered. The sample was employed in TLC plates $(200 \mu$ m layer thick, $10 \times 10$ cm silica gel-60, mean particle size of $10-12 \mu \mathrm{m}$, precoated with UV254 and aluminum-backed) for phenolics, alkaloids, flavonoids, steroids, and tannins. They were sprayed with staining reagents including alcoholic ferric chloride, Dragendorff reagent, 10\% methanolic sulfuric acid, anisaldehyde sulfuric acid, and vanillin respectively. Different solvent systems revealed various visible bands. Besides, invisible bands on TLC plates in daylight were screened using ultraviolet light.

\section{Fourier-transformed infrared spectra}

For FTIR analysis, lyophilized extracts were used, because it increases the intensity of spectral bands as it removes water and methanol interference. FTIR spectra were recorded on Bruker alpha eco atr, Optics, Germany, in conjunction with an attenuated total reflectance (ATR), incorporated with a reflection crystal $(\mathrm{ZnSe})$. The spectra were achieved at $20^{\circ} \mathrm{C}$ with an average of 128 scans, ranging frequency from 3500 to $500 \mathrm{~cm}^{-1}$, processing software OPUS (v.5.5, Bruker Optics, Germany) for a quick scan. For background, the air spectrum was recorded and subtracted spontaneously with suitable software [24].

\section{Total phenolic content}

For measuring total phenolic content (TPC) of samples, the Folin-Ciocalteu assay was followed. At this method, solutions of $7.5 \% \mathrm{w} / \mathrm{v}, \mathrm{Na}_{2} \mathrm{CO}_{3}$, and $10 \% \mathrm{v} / \mathrm{v}$ FolinCiocalteu reagent (Sigma-Aldrich Co., Germany) were formulated. Then, $0.75 \mathrm{ml}$ of Folin-Ciocalteu reagent was added to $100 \mu \mathrm{l}$ extract and was stored in the dark $\left(5 \mathrm{~min}, 20^{\circ} \mathrm{C}\right.$ ). Next, $7.5 \mathrm{w} / \mathrm{v}$ of $0.75 \mathrm{ml} \mathrm{Na}{ }_{2} \mathrm{CO}_{3}$ solution was mixed and kept in the dark $\left(90 \mathrm{~min}, 20^{\circ} \mathrm{C}\right.$ ) and mixed randomly until a homogenous solution was achieved. Lastly, using a spectrophotometer (Thermo Fisher EVO300PC, USA) at $765 \mathrm{~nm}$, the absorbance was estimated and compared with the calibration curve, which was formulated applying known quantities of gallic acid. The findings are measured as milligrams of gallic acid equivalent (GAE)/100 g [25].

\section{Antioxidant assay DPPH dissolvent}

The $0.01 \mathrm{mM}$ DPPH $\left(\mathrm{C}_{18} \mathrm{H}_{12} \mathrm{~N}_{5} \mathrm{O}_{6}\right.$, M.W. $\left.394.32 \mathrm{~g} / \mathrm{mol}\right)$ dissolvent was formulated by dissolving $1.9716 \mathrm{mg}$ of DPPH (2,2-diphenyl-1-picrylhydrazyl) in $500 \mathrm{ml}$ methanol.

\section{DPPH radical scavenging assay}

Antioxidant activity was measured by DPPH radicalscavenging assay given by Brand-Williams [26] with several alterations. The fresh stock solution $0.01 \mathrm{mM}$ of DPPH (Sigma-Aldrich Co., Germany) was prepared by dissolving in methanol (SRL, Mumbai, India). $2.7 \mathrm{ml}$ of prepared DPPH was added to various concentrations of samples $(20-200 \mu \mathrm{g} / \mathrm{ml})$, which was then incubated in pitch-dark for $15 \mathrm{~min}$ at ambient temperature $\left(20^{\circ} \mathrm{C}\right)$. A gradual decline in absorbance was determined at $517 \mathrm{~nm}$ in a spectrophotometer (Thermo Fisher EVO 300PC, USA). Ascorbic acid (SRL, Mumbai, India) solution of the same concentration can be used as a positive control for the free radical scavenging assay. The test was conducted in three replicates. The findings were expressed in $\mathrm{IC}_{50}$ value, ascertained by plotting the percentage of scavenging activity against concentration.

The potential ability to scavenge DPPH free radical was estimated by the below equation:

\%inhibition ratio $=\frac{\text { Absorbance of the control }- \text { Absorbance of the tested compound }}{\text { Absorbance of the control }} \times 100$

- Absorbance of control = absorbance of solution that contain all reagents except sample

- Absorbance of compound = absorbance of sample or standard

\section{Antimicrobial test Antibacterial test}

The antibacterial activity of crude extract of S. urens roots was checked against bacterial strains Escherichia coli, Bacillus subtilis, and Klebsiella pneumoniae by employing agar well diffusion assay [27]. Obtained bacterial cultures were maintained at $37^{\circ} \mathrm{C}$ in Mueller Hinton nutrient broth (Himedia, Mumbai, India). The bacterial cell suspension culture was prepared in sterile saline water, and it was optimized to 0.5 McFarland turbidity standards with the help of a spectrophotometer to achieve the desired cell density $(1.5 \times 108 \mathrm{cfu} / \mathrm{ml})$. Each bacterial culture uniformly streaked on Mueller Hinton agar plates, and $100 \mu \mathrm{l}$ hydro-methanolic root extract was filled in the wells with 200 and $300 \mu \mathrm{g} / \mathrm{ml}$ concentration. Bacterial plates were kept at temperature $37^{\circ} \mathrm{C}$ and incubated for about $24 \mathrm{~h}$. Later, antimicrobial activity was reckoned by measuring the inhibition zone.

\section{Antifungal test}

The experiment of diffusion in agar well was performed in compliance with the Clinical Laboratory Standard Institute document M51-A2 [25], with several adaptations. Initially, species were cultured in Sabouraud's agar medium (Himedia, Mumbai, India), which was kept at $30{ }^{\circ} \mathrm{C}$ temperature for 7 days of incubation. The fungal 
spore suspension culture of Penicillium glaucum was prepared using sterile PBS (phosphate-buffered saline). Spore concentrations were standardized using haemocytometer to 105 spores $/ \mathrm{ml}$ limit. The root extract $(50 \mu \mathrm{l})$ was added with a concentration of 150 and $250 \mu \mathrm{g} / \mathrm{ml}$, after punching the agar plates with a sterilized cork borer ( $2 \mathrm{~cm}$ in diameter). The plates were then kept at $30^{\circ} \mathrm{C}$ temperature for $48 \mathrm{~h}$ immediately followed by the measurement of inhibition halos.

\section{Statistical analysis}

Each value obtained is an aggregate of three replicas, and it was denoted as mean \pm standard deviation. All the recorded data were analysed with the help of the statistical tool of the Window's statistical software package SPSS (release 8.0). The test of significance was conducted by oneway analysis of variance (ANOVA; $P<0.05$ ).

\section{Results}

\section{Yield value and extract properties}

The present study highlights yield value to quantify the number of active constituents relative to the amount of the crude drug material which was found co-related. Hydro-methanolic root extract recorded significantly high yield by $5.68 \%$, along with the physical properties like the color (dark red), stickiness (non-sticky), and appearance (dry solid).

The formula used for calculating the yield value of crude methanol extract follows:

$$
\begin{aligned}
\% \text { yield }= & \frac{\text { The final weight of extract } \text { obtained }}{\text { The initial weight of extract }} \\
& \times 100
\end{aligned}
$$

\section{Preliminary phytochemical screening}

Hydro-methanolic root extract exhibited the presence of tannins, flavonoids, alkaloids, phenols, saponins, glycosides, steroids, and proteins and the absence of carbohydrate or sugar. Besides, methanol efficiently extracted phytochemical constituents indicating maximum polar molecules like phenolics (Table 1).

\section{Thin-layer chromatography}

The number of compounds in the extracts was calculated using the TLC method of analysis. The chromatographic spots which were representative of compounds in the various extracts were observed, and their $\mathrm{Rf}$ values determined (Table 2). The extract exhibited the separation of phenolics with a yellowish-brown spot having the highest $R f$ value of 0.92 , whereas separation of alkaloids revealed a yellowish spot was having $\mathrm{R} f$ value 0.72 in visible light, red and blue at UV365. Further, flavonoids resulted in a brown spot having an $\mathrm{R} f$ value of
0.84 in visible light, orange, red, and green at UV365. TLC assay separated steroids with purplish spot having $\mathrm{R} f$ value 0.74 in visible light, red and blue at UV365. The analysis showed the presence of tannins with a greenishbrown spot (visible), red and blue at UV365, having the lowest $R f$ value of 0.52. $R f$ values denote relative migration, while absolute values vary by position based on different parameters, including humidity and temperature.

\section{Fourier-transformed infrared (FT-IR) spectra analysis}

Hydro-methanolic dried root extract was measured sourcing ATR-FTIR (Fig. 3) to analyze functional groups and to identify the peaks characteristic of each species. The possible functional groups and peak value interpretation (obtained by FTIR analysis) are shown in Table 3 . Eighteen significant bands were spotted between 500 and $4000 \mathrm{~cm}^{-1}$; the transmission was converted into absorbance, and evaluation was generated. Band (A) at $529 \mathrm{~cm}^{-1}$, (B) at $546 \mathrm{~cm}^{-1}$, and (C) at $576 \mathrm{~cm}^{-1}$ appeared as three small peaks, which could indicate the $\mathrm{C}$-halogen (Out-of-plane-ring bending). Fourth band (D) was distinguished at $631 \mathrm{~cm}^{-1}$, representing skeletal vibration of $\mathrm{C}-\mathrm{Cl}$, an alkyl aldehyde stretches, and at $763 \mathrm{~cm}^{-1}$, the band $(\mathrm{E})$ detects $\mathrm{C}-\mathrm{H}$ vibration indicating alkene structure. A sharp infrared band (F) at $1063 \mathrm{~cm}^{-1}$ was visualized, representing a $\mathrm{C}-\mathrm{O}$ stretch of primary alcohol. Similarly, a peak at $1111 \mathrm{~cm}^{-1}$ (G) revealed $\mathrm{C}-\mathrm{H}$ wag bending vibration of alkyl halide. A peak of medium intensity was spotted at $1156 \mathrm{~cm}^{-1}(\mathrm{H})$, exhibiting $\mathrm{C}-\mathrm{O}$ band verifying a tertiary alcohol group. A $\mathrm{C}-\mathrm{O}-\mathrm{C}$ stretch of aromatic amine is detected as band (I) at $1280 \mathrm{~cm}^{-1}$. Between the frequency range of $1550-1300$, three bands appeared at $1373 \mathrm{~cm}^{-1}(\mathrm{~J}), 1446 \mathrm{~cm}^{-1}(\mathrm{~K})$, and $1517 \mathrm{~cm}^{-1}(\mathrm{~L})$, assigning bands of $\mathrm{C}-\mathrm{H}, \mathrm{C}-\mathrm{H}$, and $\mathrm{NH}$ indicating possible groups like alkanes, alkanes, and secondary amines respectively, while stretching of $\mathrm{C}=\mathrm{C}$ indicates vibrations of alkenes on band $(\mathrm{M})$ at a strong peak of $1610 \mathrm{~cm}^{-1}$. Likewise, bands of medium intensity were recognized at $2085 \mathrm{~cm}^{-1}(\mathrm{~N})$ and $2357 \mathrm{~cm}^{-1}(\mathrm{O})$; the vibrations correspond to amide and carboxylic acid stretch respectively.

Band (P) $2852 \mathrm{~cm}^{-1}$ and (Q) $2921 \mathrm{~cm}^{-1}$ indicate a strong stretch of $\mathrm{C}-\mathrm{H}$ corresponding to an alkane group. At $3356 \mathrm{~cm}^{-1}(\mathrm{R})$, a broad intensity peak was detected, which is specifying $\mathrm{OH}$ vibration of alcohol, aldehyde, or carboxylic acid.

\section{Total phenolic content analysis}

The $90 \%$ root extract consisted of a significant amount of total phenolic content with $705 \pm 0.40 \mathrm{mg} \mathrm{GAE} / \mathrm{g} \mathrm{DE}$. The calibrated curve equation is described below. 
Table 1 Phytochemical analysis of hydro-methanolic extract of Sterculia urens Roxb. root

\begin{tabular}{|c|c|c|c|c|c|}
\hline Phytochemi & & & & & \\
\hline Alkaloid & Wagner's test & + & Tannins & Potassium dichromate test & + \\
\hline & Dragendorff test & + & & Lead acetate test & + \\
\hline & Mayer's test & + & & Ferric chloride test & + \\
\hline Flavonoids & Pew test & + & Steroids & Libermann sterol test & + \\
\hline & Shinoda test & + & & Acetic anhydride test & + \\
\hline & Alkaline reagent test & + & & Libermann Buchard test & + \\
\hline & Zinc hydrochloride reduction test & + & Sugar/carbohydrates & lodine Test & - \\
\hline Phenols & Alkaline reagent test & - & & Fehling's test & - \\
\hline & Lead acetate test & + & & Molisch's test & - \\
\hline & Ferric chloride test & + & & Benedict's test & - \\
\hline & Potassium dichromate test & + & Proteins/amino acids & Xanthoproteic & $t$ \\
\hline Saponins & Frothing test & + & & Ninhydrin test & + \\
\hline Glycosides & Killer-Killiani test & + & & Million's test & 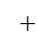 \\
\hline
\end{tabular}

Note: $(+)=$ present; $(-)=$ absent

$$
y=0.0345 x+0.9659 ; R^{2}=0.9683
$$

The current study investigated and confirmed that the hydro-methanolic extract of $S$. urens root represents high phenolic content as well as antioxidant activity.

\section{Antioxidant activity}

The DPPH assay is often used to test the antioxidant potential of the natural compounds. It is known as one of the standards and an effective and rapid method for colorimetric evaluation of antioxidant properties of biological samples. The basic principle of the assay is that the DPPH is a stable molecule that tends to absorb at $515 \mathrm{~nm}$ and gives purple colour in methanol. The reduction of DPPH by the antioxidant agent has resulted in a change from purple to yellow colour with a consequent decline in absorbance at $515 \mathrm{~nm}$, which is monitored by spectrophotometer [28]. In the present investigation, the DPPH radicals were used for the determination of the prospective antioxidant properties of S. urens root. Ascorbic acid was chosen for positive control. Findings were expressed as $50 \%$ inhibition concentration $\left(\mathrm{IC}_{50}\right)$ computed from the linear regression equation obtained

through a plot of concentration against the percentage of inhibition (Fig. 4). The lower $\mathrm{IC}_{50}$ value of the compound indicates its stronger antioxidant properties [29]. In this study, the $\mathrm{IC}_{50}$ value of a hydro-methanolic plant extract and ascorbic acid was estimated to be $27.055 \mu \mathrm{g} /$ $\mathrm{ml}$ and $37.244 \mu \mathrm{g} / \mathrm{ml}$, respectively, which suggests that root extract possesses strong antioxidant properties.

\section{Antimicrobial activity}

The present investigation of antimicrobial potency of hydro-methanolic extract of $S$. urens roots was tested against two strains of gram-negative bacteria Escherichia coli (E. coli) and Klebsiella pneumoniae (K. pneumoniae), one gram-positive bacteria strain Bacillus subtilis (B. subtilis), and one fungal species Penicillium glaucum ( $P$. glaucum) by measuring the zone of inhibition (Fig. 5). For E. coli, the result obtained from the current investigation shows a higher zone of inhibition, $30 \mathrm{~mm}$ and 50 $\mathrm{mm}$ for $200 \mu \mathrm{g} / \mathrm{ml}$ and $300 \mu \mathrm{g} / \mathrm{ml}$ concentration of root extract, respectively, which indicates good antimicrobial activity against $E$. coli bacteria.

The results of the current study revealed that root extract with a concentration of $300 \mu \mathrm{g} / \mathrm{ml}$ shows significant

Table 2 Thin layer chromatography of hydro-methanolic extract of Sterculia urens Roxb. root

\begin{tabular}{|c|c|c|c|c|c|}
\hline \multirow{2}{*}{$\begin{array}{l}\text { Compound } \\
\text { name }\end{array}$} & \multirow[t]{2}{*}{ Solvent system } & \multirow[t]{2}{*}{ Confirmatory test } & \multicolumn{2}{|l|}{ Spot band colour } & \multirow{2}{*}{$\begin{array}{l}R_{f} \\
\text { value }\end{array}$} \\
\hline & & & Visible light & Ultraviolet $365 \mathrm{~nm}$ & \\
\hline Phenolics & Toluene to acetone (9:1) & Alcoholic ferric Chloride & Brownish-yellow & $\mathrm{NII}$ & 0.92 \\
\hline Alkaloid & Diethylamine to methanol (8:1:1) & Dragendorff reagent & Yellow & Blue, red & 0.72 \\
\hline Flavonoid & $\begin{array}{l}\text { Glacial acetic acid to ethyl acetate to formic } \\
\text { acid to water (0.5:10:0.5:1.3) }\end{array}$ & $10 \%$ methanolic sulfuric acid & Brown & Orange, red, green & 0.84 \\
\hline Steroid & Butanol to methanol to water $(16: 4: 0.2)$ & $10 \%$ methanolic sulfuric acid & Purple & Blue, red & 0.74 \\
\hline Tannins & Methanol to chloroform: to water (35:65: 10) & Vanillin solution & Brownish green & Blue, red & 0.52 \\
\hline
\end{tabular}




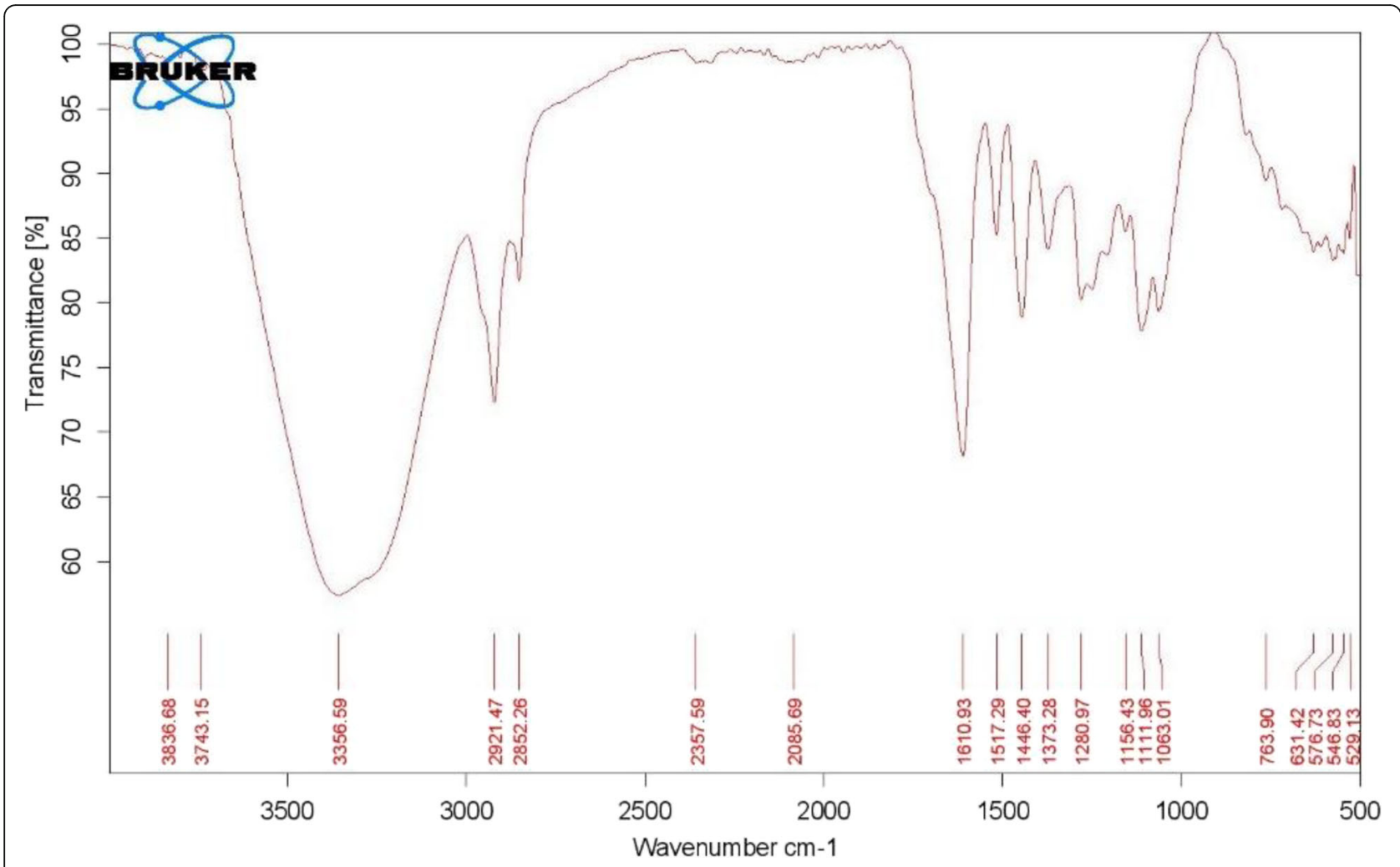

Fig. 3 The FTIR spectrum showing peak values of hydro-methanolic root extract

Table 3 FT-IR analysis revealed the presence of functional groups in the Sterculia urens Roxb. root

\begin{tabular}{|c|c|c|c|c|c|}
\hline Frequency range & Band & Band location $\mathrm{cm}^{-1}$ & Band interaction & Band assignments & Possible compounds \\
\hline \multirow[t]{3}{*}{$800-400$} & $A, B, C$ & $529,546,576$ & Out-of-plane ring bending & C-halogen & Halogen compounds \\
\hline & $\mathrm{D}$ & 631 & Stretch & $\mathrm{C}-\mathrm{Cl}$ & Alkyl halides \\
\hline & E & 763 & Stretch & $\mathrm{C}-\mathrm{H}$ & Alkenes \\
\hline $1100-800$ & $\mathrm{~F}$ & 1063 & Stretch & $\mathrm{C}-\mathrm{O}$ & Primary alcohol \\
\hline \multirow[t]{3}{*}{$1300-1000$} & G & 1111 & Stretch & $\mathrm{C}-\mathrm{H}$ wag & Alkyl halides \\
\hline & $\mathrm{H}$ & 1156 & Stretch & $\mathrm{C}-\mathrm{O}$ & Tertiary alcohol \\
\hline & । & 1280 & Stretch & $\mathrm{C}-\mathrm{O}-\mathrm{C}$ & Aromatic amine \\
\hline \multirow[t]{2}{*}{ 1550-1300 } & $J, K$ & 1373,1446 & Bend & $\mathrm{C}-\mathrm{H}$ & Alkanes \\
\hline & $\mathrm{L}$ & 1517 & Bend & $\mathrm{NH}$ & Secondary amines \\
\hline $1650-1550$ & M & 1610 & Stretch & $C=C$ & Alkenes \\
\hline \multirow[t]{2}{*}{$2800-2000$} & $N$ & 2085 & Bend & $\mathrm{C}=\mathrm{N}$ & Amide group \\
\hline & $\mathrm{O}$ & 2357 & Stretch & $\mathrm{C}-\mathrm{O}$ & Carboxylic acid \\
\hline \multirow[t]{2}{*}{$3000-2800$} & $P$ & 2852 & Stretch & $\mathrm{C}-\mathrm{H}$ & Alkane \\
\hline & Q & 2921 & Stretch & $\mathrm{C}-\mathrm{H}$ & Alkane \\
\hline $3700-3100$ & $\mathrm{R}$ & 3356 & Stretch & $-\mathrm{OH}$ & Alcohol, aldehyde, carboxylic acid \\
\hline
\end{tabular}




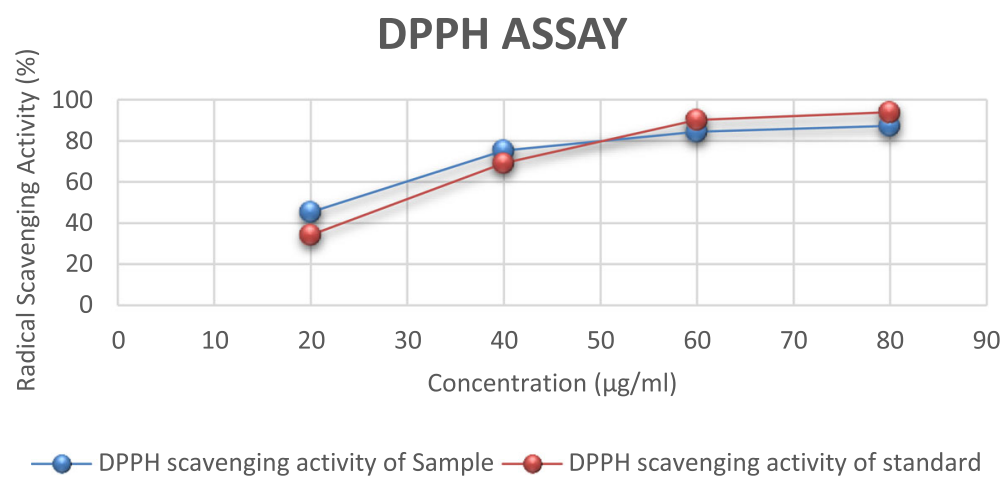

Fig. 4 Comparative analysis of radical scavenging activity(percentage) among Sterculia urens Roxb. root extract and ascorbic acid

antimicrobial activity (zone of inhibition $35 \mathrm{~mm}$ ) against K. pneumoniae. In contrast, root extract with a concentration of $200 \mu \mathrm{g} / \mathrm{ml}$ shows limited antimicrobial activity (zone of inhibition $18 \mathrm{~mm}$ ).

In this study, we found that root extract was ineffective for B. subtilis strain. Penicillium is the most familiar and widespread fungus; several members of the genus produce the antibiotic penicillin while others are used to make cheese [30]. Hydro-methanolic extract of S. urens root with concentrations of $200 \mu \mathrm{g} / \mathrm{ml}$ and $300 \mu \mathrm{g} / \mathrm{ml}$ showed $45 \mathrm{~mm}$ and $25 \mathrm{~mm}$ zone of inhibition, respectively, which indicates unusual antifungal activity against P. glaucum.

\section{Discussion}

At present, research in herbal medicines and their natural substances is substantially focused. S. urens has its traditional significance in treating different human diseases. Moreover, ethnomedicinally, its roots are used for facilitating childbirth, relieving constipation, and reducing body swelling [31]. For utilizing this plant in modern therapeutic systems, rigorous experimental evidence, toxicity analyses, and human clinical trials are needed.
Henceforth, the main purpose of this research was to investigate and elucidate the medicinal values of $S$. urens. This is a first study that we are reporting since there is less prior literature on the phytochemical characterization of the root. Consequently, Sterculia urens Roxb. was selected and standardized on their physicochemical parameters such as extractive values, phytochemical study, qualitative estimation, TPC, TLC along with FTIR analysis, antioxidant activity, and antimicrobial activity for the examination.

Yield value of $S$. urens root extract is noteworthy which suggests that the plant contains a variable number of active constituents or relative amounts of soluble compounds in methanol extract. There will be common secondary metabolites found in two distinct species of a similar genus. It has been claimed that the genus Sterculia includes phenolics, steroids, terpenes, alkaloids, and flavonoids, but literature on $S$. urens root chemistry is not yet documented. It poses a challenge when it comes to discovering new constituents from S. urens root. Moreover, several biological activities in genus Sterculia like Sterculia tavia-anti-proliferative activity, Sterculia villosa-antidiabetic activity, Sterculia guttata-larvicidal activity, Sterculia foetida-anti-fertility and anti-inflammatory activity,

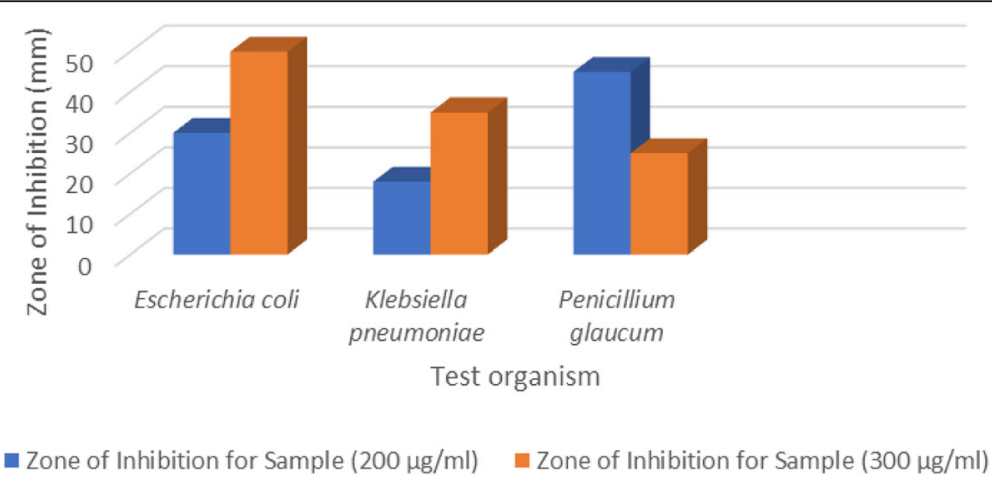

Fig. 5 Antimicrobial activities of Sterculia urens Roxb. root extract on various micro-organisms as determined by the agar well diffusion method 
and Sterculia quadrifida-antioxidant activity are studied [32]. Despite a successful investigation into the genus Sterculia, S. urens was underexplored for its chemical constituents and biological activities. Further, experiments are underway to isolate and classify bioactive substances obtained from $S$. urens. Later, bioactive phytoconstituents were confirmed using TLC.

S. urens displayed notable concentration of TPC which is supported by various studies in the same genera. $S$. quadrifida root is traditionally known to cure diabetes and cancer-like ailments. The findings obtained in our analysis for TPC are higher than the results published by Lulan et al. [32], who reported a maximum of $116.84 \pm$ $1.22 \mathrm{mg}$ of GAE/100 gS. quadrifida extracted with methanol. Few researchers stated total phenolic content values of S. oblongata bark ranges from 100 to $600 \mathrm{mg}$ GAE/g with chloroform, ethyl acetate, and methanol extracts which supports the phenolic content of the current study [33]. Phenolic compounds act as antioxidant because of their redox properties. According to Annapandian and Rajagopal [34], TPC substantially impacts its antioxidant activity, which is crucial for radical scavenging. Several studies claimed to have phenolics as crucial substances showing different biological activity and medicinal properties.

The synergistic role of the phytochemicals can serve as a natural cure for oxidative damage resulting in chronic inflammation. Corresponding outcomes were reported by Haque et al. [35], in crude methanolic extract of $S$. villosa bark ( $\mathrm{IC}_{50}$ value $27.28 \mu \mathrm{g} / \mathrm{ml}$ ), and Dillak et al. [36], in the ethanolic extract of S. quadrifida root ( $\mathrm{IC}_{50}$ value $20.55 \pm 0.42$ ). The result derived from this analysis was in good agreement towards earlier reports suggesting the use of methanol extract for the radical scavenging activity analysis [37]. Different metabolic processes of the living system produce reactive species called free radicals; they spread throughout the body and damage important biomolecules of the body by disrupting their structure and interfering with their function, leading to cellular dysfunction and cell death. This can result in serious health problems such as cancer and ageing, which can be prevented by radical scavenging potential of flavonoid and phenolics [38].

Since the last few decades, multiple antibiotic drug resistance has been acquired by pathogenic bacteria. For that, alternative strategies are required to combat antibiotic resistance. Escherichia coli is a widely occurring bacterium in human's intestine and homeothermic organisms. The vast majority of $E$. coli strains are innocuous. Nonetheless, a few other strains, including enterohemorrhagic $E$. coli, may cause severe foodborne diseases. In general, $K$. pneumoniae is an encapsulated, non-motile opportunistic pathogen that is found in the environment and targets principally people with compromised immune systems and causes nosocomial infection. K. pneumoniae is also responsible for various diseases like urinary tract, bloodstream, and septic infection [39, 40]. The presence of considerate phytoconstituents like phenolics, alkaloids, flavonoids, saponins, terpenoids, glycosides, tannins, and steroids in root extract might be the reason behind its significant in vitro antioxidant and antimicrobial activity. Such results offer a comparable bioactivity study and serve as an example of their future application in the pharmaceutical and food industries.

\section{Conclusion}

The principal objective of the study is to identify the presence of different secondary metabolites, their functional groups, antioxidant and antimicrobial activity of Sterculia urens root. The presence of these bioactive metabolites implies that the hydro-methanolic root extract of $S$. urens has quite a few pharmaceutical products that would have quite several medicinal applications. It showed high phenolic content, which is a valuable reference for antioxidant properties. The extract of root exhibited high DPPH radical scavenging activity, indicating S. urens as a potential candidate for antioxidant study for further studies. Additionally, isolation, purification, and characterization of the phytochemicals will make remarkable studies. This primary information will simplify in leading further studies on the discovery of bioactive ingredients, resolve their efficacy by in vivo studies, and demonstrate their safety and effectiveness in clinical trials. The study suggests that crude extract possesses promising antimicrobial and antioxidant activity; thus, organic antioxidant and antimicrobial medicines can be generated for possible therapeutic applications. This is the fundamental collective report on phytochemical screening, TLC, TPC, FTIR, antioxidant, and antimicrobial activity on the roots of Sterculia urens Roxb.

\section{Abbreviations \\ DE: Dried extract; DPPH: 1,1-Diphenyl-2-picrylhydrazyl; FC: Folin-Ciocalteu; FT- IR: Fourier transform infrared; GAE: Gallic acid equivalent; $\mathrm{Na}_{2} \mathrm{CO}_{3}$ : Sodium carbonate; TLC: Thin layer chromatography; TPC: Total phenolic content; PBS: Phosphate buffer saline}

\section{Acknowledgements \\ The authors are thankful to the authorities of Gujarat University, Ahmedabad, Gujarat, India.}

\section{Study involving plants}

1. The plant material was authenticated by Dr. Bharat Maitreya. The herbarium specimen was deposited in Plant Systematics Division,

Department of Botany, Bioinformatics and Climate Change Impacts Management, Gujarat University, India, with reference ID (GUSU-01).

2. As per the local and national guidelines and legislation and the required

or appropriate permissions and/or licenses for the study.

\section{Authors' contributions}

AS analysed and interpreted the data regarding the phytochemical characterization and bioassay and inscribed the major part of the manuscript. KD performed significant contribution in writing the manuscript. 
NM was associated in supervising, advising, positioning, and structuring the manuscript. All authors read and approved the final manuscript.

\section{Funding}

No funding was sourced.

\section{Availability of data and materials}

All data and material are available upon request.

\section{Ethics approval and consent to participate}

Not applicable.

\section{Consent for publication}

Not applicable.

\section{Competing interests}

No competing interest to declare.

Received: 30 May 2020 Accepted: 20 July 2020

Published online: 31 July 2020

\section{References}

1. Arunachalam KD, Subhashini S, Annamalai SK (2012) Wound healing and antigenotoxic activities of Aegle marmelos with relation to its antioxidant properties. J Pharm Res 5(3):1492-1502

2. Figueiredo, A., Fortes, A. M., Ferreira, S., Sebastiana, M., Choi, Y. H., Sousa, L., \&amp; Pais, M. S. (2008). Transcriptional and metabolic profiling of grape (Vitis vinifera L.) leaves unravel possible innate resistance against pathogenic fungi. Journal of experimental Botany, 59(12), 3371-3381. https://doi.org/10. 1093/jxb/ern187 PMID:18648103

3. Svoboda, K. P., Svoboda, T. G., \& Syred, A. D. (2000). Secretory structures of aromatic and medicinal plants. Microscopix., https://doi.org/10.1006/anbo. 2000.1279

4. Kumar A, Irchhaiya R, Yadav A, Gupta N, Kumar S, Gupta N et al (2015) Metabolites in plants and its classification. World J Pharm Pharm Sci 4(1): 287-305

5. Fabricant, D. S., \& Farnsworth, N. R. (2001). The value of plants used in traditional medicine for drug discovery. Environ Health Perspect, 109(Suppl 1), 69-75. https://doi.org/10.1289/ehp.01109s169 PMID:11250806

6. Imaida, K., Fukushima, S., Shirai, T., Ohtani, M., Nakanishi, K., \& Ito, N. (1983). Promoting activities of butylated hydroxyanisole and butylated hydroxytoluene on 2-stage urinary bladder carcinogenesis and inhibition of Y-glutamyl transpeptidase-positive foci development in the liver of rats. Carcinogenesis, 4, 895-899. https://doi.org/10.1093/carcin/4.7.895 PMID: 6135514

7. Ito, N., Hirose, M., Fukushima, S., Tsuda, H., Shirai, T., \& Tatematsu, M. (1986). Studies on antioxidants: their carcinogenic and modifying effects on chemical carcinogenesis. Food Chem Toxicol, 24, 1071-1082. https://doi. org/10.1016/0278-6915(86)90291-7 PMID:3804112

8. Movasaghi Z, Rehman S, Rehman IU (2008) Fourier transform infrared spectroscopy of biological tissues. Appl Spectrosc Rev 43:134-179 https:// doi.org/10.1080/05704920701829043

9. Takeoka, G. R., \& Dao, L. T. (2003). Antioxidant constituents of almond [Prunus dulcis (Mill.) D.A. Webb] hulls. J Agric Food Chem, 51, 496-501. https://doi.org/10.1021/jf020660i PMID:12517116

10. Yadav A, Kumari R, Yadav A, Mishra JP, Srivatva S, Prabha S (2016) Antioxidants and its functions in human body-a review. Res Environ Life Sci 9(11):1328-1331

11. Alam, M. N., Bristi, N. J., \& Rafiquzzaman, M. (2013). Review on in vivo and in vitro methods evaluation of antioxidant activity. Saudi Pharmaceutical Journal, 21(2), 143-152. https://doi.org/10.1016/j.jsps.2012.05.002 PMID: 24936134

12. Pham, H. N. T., Vuong, Q. V., Bowyer, M. C., \& Scarlett, C. J. (2017). Effect of extraction solvents and thermal drying methods on bioactive compounds and antioxidant properties of Catharanthus roseus (L.) G. Don (Patricia White cultivar). Journal of Food Processing and Preservation, 41, e13199. https://doi.org/10.1111/jfpp.13199

13. Pereira DM, Faria J, Gaspar L, Ferreres F, Valentao P, Sottomayor M, Andrade PB (2010) Exploiting Catharanthus roseus roots: source of antioxidants. Food Chem 121:56-61 https://doi.org/10.1016/j.foodchem.2009.12.002
14. Olivier MT, Muganza FM, Shai L, Gololo SS, Nemutavhanani LD (2017) Phytochemical screening, antioxidant and antibacterial activities of ethanol extracts of Asparagus suaveolens aerial parts. S Afr J Bot 108:41-46 https:// doi.org/10.1016/j.sajb.2016.09.014

15. Gupta D, Dubey J, Kumar M (2016) Phytochemical analysis and antimicrobial activity of some medicinal plants against selected common human pathogenic microorganisms. Asian Pacific Journal of Tropical Disease 6(1): 15-20 https://doi.org/10.1016/S2222-1808(15)60978-1

16. El-Sherei MM, Ragheb AY, Kassem MES, Marzouk MM, Mosharrafa SA, Saleh NAM (2016) Phytochemistry, biological activities and economical uses of the genus Sterculia and the related genera: a review. Asian Pacific Journal of Tropical Disease 6(6):492-501 https://doi.org/10.1016/S2222-1808(16)61075-7

17. Galla NR, Dubasi GR (2010) Chemical and functional characterization of Gum karaya (Sterculia urens L.) seed meal. Food Hydrocoll 24(5):479-485 https://doi.org/10.1016/j.foodhyd.2009.12.003

18. Dhiman M, Singh A, Sharma MM (2019) A review on Sterculia urens Roxb:: a boon to the livelihood for tribal people and industry. Ind Crop Prod 130: 341-351 https://doi.org/10.1016/j.indcrop.2018.12.065

19. Sunnichan VG, Ram HM, Shivanna KR (2004) Floral sexuality and breeding system in gum karaya tree, Sterculia urens. Plant Syst Evol 244(3-4):201-218 https://doi.org/10.1007/s00606-003-0095-x

20. Silori CS, Mehar M, Khalid MA, Paul V (2005) Non-Timber forest products: conservation status and management priorities in the community managed forests of Andhra Pradesh, South India. Int J Sust Dev World 12(3):334-346 https://doi.org/10.1080/13504500509469643

21. Alebiosu CO, Yusuf AJ (2015) Phytochemical screening, thin-layer chromatographic studies and UV analysis of extracts of Citrullus lanatus. J Pharm Chem Biol Sci 3(2):214-220

22. Rafi KP, Karthikeyan M, Kannan M, Rajasekar S (2011) Anthelmintic activity of Nerium olender flower extract in Indian adult earthworm. J Nat Prod Plant Res 1(4):40-46

23. Kokate CK, Purohit AP, Gokhale SB (2001) Carbohydrate and derived products, drugs containing glycosides, drugs containing tannins, lipids and protein alkaloids. Text book of Pharmacognosy 7:133-166

24. Lu, X., Wang, J., Al-Qadiri, H. M., Ross, C. F., Powers, J. R., Tang, J., \& Rasco, B. A. (2011). Determination of total phenolic content and antioxidant capacity of onion (Allium cepa) and shallot (Allium oschaninii) using infrared spectroscopy. Food Chem, 129(2), 637-644. https://doi.org/10.1016/j. foodchem.2011.04.105 PMID:30634280

25. Clinical and Laboratory Standards Institute. "Method for antifungal disk diffusion susceptibility testing of yeasts." CLSI Document M44-A2 (2009): 1-25.

26. Brand-Williams W, Cuvelier ME, Berset CLWT (1995) Use of a free radical method to evaluate antioxidant activity. Lebensmittel-Wissenschaft + Technologie 28(1):25-30 https://doi.org/10.1016/S0023-6438(95)80008-5

27. Moe, T. S., Win, H. H., Hlaing, T. T., Lwin, W. W., Htet, Z. M., \& Mya, K. M. (2018). Evaluation of in vitro antioxidant, antiglycation and antimicrobial potential of indigenous Myanmar medicinal plants. Journal of Integrative Medicine, 16(5), 358-366. https://doi.org/10.1016/j.joim.2018.08.001 PMID: 30120077

28. Mishra K, Ojha H, Chaudhury NK (2012) Estimation of antiradical properties of antioxidants using DPPH assay: a critical review and results. Food Chem 130(4):1036-1043 https://doi.org/10.1016/j.foodchem.2011.07.127

29. Daoud A, Malika D, Bakari S, Hfaiedh N, Mnafgui K, Kadri A, Gharsallah N (2019) Assessment of polyphenol composition, antioxidant and antimicrobial properties of various extracts of Date Palm Pollen (DPP) from two Tunisian cultivars. Arab J Chem 12(8):3075-3086 https://doi.org/10. 1016/j.arabjc.2015.07.014

30. Yadav, A. N., Verma, P., Kumar, V., Sangwan, P., Mishra, S., Panjiar, N., \& Saxena, A. K. (2018). Biodiversity of the genus Penicillium in different habitats. In New and future developments in microbial biotechnology and bioengineering (pp. 3-18). Elsevier., https://doi.org/10.1016/B978-0-444-63501-3.00001-6

31. Yadav R, Yadav A (2008) Phenology of selected woody species in a tropical dry deciduous forest in Rajasthan, India. Trop Ecol 49:25-34

32. Lulan TYK, Fatmawati S, Santoso M, Ersam T (2018) Antioxidant capacity of some selected medicinal plants in East Nusa Tenggara, Indonesia: the potential of Sterculia quadrifida R. Br Free Radicals and Antioxidants 8(2):96101 https://doi.org/10.5530/fra.2018.2.15

33. Murningsih T, Praptiwi $P$, Liana L, Fathoni A, the MURNINGSIH (2019) TLC profiling and antioxidant activity of phenolic compound from Sterculia oblongata bark extract. Nusantara Bioscience 11(1):44-48 https://doi.org/10. 13057/nusbiosci/n110108 
34. Annapandian VM, Rajagopal SS (2017) Phytochemical evaluation and in vitro antioxidant activity of various solvent extracts of Leucas aspera (Willd.) Link leaves. Free Radicals and Antioxidants 7(2):166-171 https://doi. org/10.5530/fra.2017.2.25

35. Haque S S-u, Rashid MMO, Prodhan MA, Noor S, Das A (2014) In vitro evaluation of antimicrobial, cytotoxic and antioxidant activities of crude methanolic extract and other fractions of Sterculia villosa barks. Journal of Applied Pharmaceutical Science 4(3):35

36. Dillak, H. I., Kristiani, E. B. E., \& Kasmiyati, S. (2019). Secondary metabolites and antioxidant activity of ethanolic extract of Faloak (Sterculia quadrifida). Biosaintifika. Journal of Biology \& Biology Education, 11(3).

37. Nyayiru Kannaian, U. P., Edwin, J. B., Rajagopal, V., Nannu Shankar, S., \& Srinivasan, B. (2020). Phytochemical composition and antioxidant activity of coconut cotyledon. Heliyon, 6(2), e03411. https://doi.org/10.1016/j.heliyon. 2020.e03411 PMID:32083218

38. Harman, D. (1992). Free radical theory of aging. Mutat Res, 275, 257-266 https://doi.org/10.1016/0921-8734(92)90030-S PMID:1383768

39. Li, B., Zhao, Y., Liu, C., Chen, Z., \& Zhou, D. (2014). Molecular pathogenesis of Klebsiella pneumoniae. Future Microbiol, 9(9), 1071-1081. https://doi.org/10. 2217/fmb.14.48 PMID:25340836

40. Bengoechea, J. A., \& Sa Pessoa, J. (2019). Klebsiella pneumoniae infection biology: living to counteract host defences. FEMS Microbiol Rev, 43(2), 123144. https://doi.org/10.1093/femsre/fuy043 PMID:30452654

\section{Publisher's Note}

Springer Nature remains neutral with regard to jurisdictional claims in published maps and institutional affiliations.

\section{Submit your manuscript to a SpringerOpen ${ }^{\circ}$ journal and benefit from:}

- Convenient online submission

- Rigorous peer review

- Open access: articles freely available online

- High visibility within the field

- Retaining the copyright to your article

Submit your next manuscript at $\boldsymbol{\nabla}$ springeropen.com 